\title{
Sustentabilidade e Governança: Evidenciação Ambiental em Empresas Prestado- ras de Serviço Sustainability and Governance: Environmental Disclosure in Service Providers
}

\author{
Sabrina Keli Salvador ${ }^{1}$ \\ Alex Eckert ${ }^{2}$ \\ Marlei Salete Mecca ${ }^{3}$ \\ Jéssica Santos Vargas ${ }^{4}$
}

\section{Resumo}

A necessidade de se utilizar os recursos ambientais de maneira adequada e sustentável deve estar cada vez mais presente no cotidiano das pessoas, do poder público e das empresas. Diante disso, este estudo tem por objetivo analisar as práticas e iniciativas ambientais adotadas em empresas prestadoras de serviços contábeis e de turismo da região da Serra Gaúcha, no estado do Rio Grande do Sul. Para atingir tal objetivo, foi realizada uma survey por meio de um questionário elaborado a partir do instrumento "Indicadores Ethos para Negócios Sustentáveis e Responsáveis" (Ethos, 2016). Os resultados indicam que as empresas pesquisadas apresentam uma preocupação com as questões relacionadas ao meio ambiente, mas essa ainda não é uma unanimidade. As empresas têm preocupação com o consumo consciente de materiais, tais como papeis e descartáveis, com o consumo de energia e água e a destinação de seus resíduos, mas deixam a desejar quando se trata de ações ambientais e comunicação com a comunidade acerca deste tema.

Palavras-chave: Meio ambiente. Iniciativas ambientais. Práticas ambientais. Escritórios contábeis. Empresas de Turismo.

\section{Abstract}

The need to use environmental resources in an adequate and sustainable manner must be increasingly present in the daily lives of people, public authorities and companies. Therefore, this study aims to analyze the environmental practices and initiatives adopted by Brazilian accounting and tourism companies. To achieve this objective, a survey was carried out through a questionnaire elaborated from the "Indicators Ethos for Sustainable and Responsible Business" (Ethos, 2016). The results indicate that the companies surveyed have a concern about environmental issues, but this is not unanimous. The companies are concerned with the conscious consumption of materials, such as paper and disposable, with the consumption of energy and water and the destination of their residues, but they do not deserve when it comes to environmental actions and communication with the community about this theme.

Keywords: Environment. Environmental initiatives. Environmental practices. Accounting Offices. Tourism companies.

\footnotetext{
${ }^{1}$ Especialização em Planejamento Tributário Contábil. Pesquisadora voluntária na Universidade de Caxias do Sul (UCS) no Programa de Pós-Graduação em Administração. Caxias do Sul, Rio Grande do Sul, Brasil. E-mail: sabrina.keli23@ hotmail.com.

2 Doutorado em Administração. Professor na Universidade de Caxias do Sul (UCS) no Programa de Pós-Graduação em Administração. Caxias do Sul, Rio Grande do Sul, Brasil. E-mail: aeckert@ucs.br.

${ }^{3}$ Doutorado em Engenharia da Produção. Professora na Universidade de Caxias do Sul (UCS) no Programa de Pós-Graduação em Administração. Caxias do Sul, Rio Grande do Sul, Brasil. E-mail: msmecca@ucs.br.

${ }^{4}$ Especialização em Administração de Empresas. Pesquisadora voluntária na Universidade de Caxias do Sul (UCS) no Programa de Pós-Graduação em Administração. Caxias do Sul, Rio Grande do Sul, Brasil. E-mail: jeh.svargas@gmail.com.
} 


\section{INTRODUÇÃO}

O impacto das atividades econômicas e sociais sobre os sistemas naturais tem causado o comprometimento de sua disponibilidade (Fugiel et al., 2017), não só para as próximas gerações, mas também para atual. As empresas, preocupadas sobremaneira com a eficácia e eficiência dos sistemas produtivos, começaram a perceber que uma visão economicista se revela insatisfatória, ficando evidente que o contexto de sua atuação a cada dia torna-se mais complexo e o processo decisório sofre restrições cada vez mais severas. Percebe-se que um dos componentes mais importantes de uma nova visão acerca dos modos de pensar e agir tem por base o crescimento da consciência ecológica, tanto na sociedade de um modo geral, quanto nos governos e nas próprias empresas (Tinoco e Robles, 2006).

O desenvolvimento econômico e tecnológico, principalmente nos dois últimos séculos, ampliou exponencialmente a produção de riqueza no mundo, sendo que em alguns casos isso significou a maximização da utilização dos recursos naturais, ignorando o fato de serem estes renováveis ou não. Entretanto, o que se percebe nas últimas décadas é que a sociedade tem cobrado tanto das empresas como do governo o desenvolvimento econômico sustentável (Lima Filho, Bruni, \& Gomes, 2013).

As organizações, por sua vez, estão cada vez mais adotando práticas de responsabilidade ambiental, seja por pressão da sociedade em geral, ou por cumprimento de políticas governamentais, já que as empresas são fatores chave para o bem-estar econômico, ambiental e social (Schaltegger, Benett, \& Burritt, 2006). A sustentabilidade empresarial é, portanto, necessária no longo prazo assim como o desenvolvimento sustentável da economia e da sociedade como um todo (Bachmann, Carneiro, \& Espejo, 2013), e a exigência de lucro e sobrevivência pode conviver harmoniosamente com a responsabilidade ambiental dentro de uma concepção mais ampla, como filosofia de operações da empresa (Ferreira, 2013).

Elkington (1998) apresenta sustentabilidade como o princípio de assegurar que as ações que são tomadas no presente não limitarão as opções econômicas, sociais e ambientais das gerações futuras. Desta forma, o desenvolvimento sustentável incorpora três princípios relacionados: integridade ambiental, equidade social e prosperidade econômica, onde o desempenho de um princípio reflete diretamente sobre o desempenho dos outros dois (Hubbard, 2009). Em um contexto colaborativo, a sustentabilidade está sendo considerada uma das formas preferidas de governança para gerenciar as relações entre as empresas (Niesten, et al. (2017).

Historicamente, países como o Brasil, que por causa do atraso em aspectos tecnológicos, educacionais e sociais, e de um elevado grau de pobreza, dão prioridade para o crescimento econômico, sem preocupações efetivas com o meio ambiente. Essa exploração da natureza sobrepõe-se à mentalidade de preservação, encontrada nos países 
considerados desenvolvidos. Assim, o Brasil tem visto a destruição ambiental como o preço (aceitável) a ser pago pelo progresso econômico, ou ainda, como uma prioridade menor considerando suas necessidades mais imeditas (Rohrich \& Cunha, 2004).

Ainda em termos de quesão ambiental, existe outra grande diferença percebida entre os países desenvolvidos e os em desenvolvimento. Enquanto os primeiros aumentam continuamente a sua capacidade tecnológica e com isso estão mais aptos a adotarem o gerenciamento ambiental, nos outros, como ocorre no Brasil, por exemplo, prevalecem as tecnologias chamadas end-of-pipe ou fim de tubo, que tratam os resíduos e efluentes somente no final do processo produtivo, sendo consideradas tecnologias de controle (Viegas \& Fracasso, 1998).

O desenvolvimento e consequente sucesso das empresas no mercado pode ter relação com as inovações tecnológicas de seus produtos e de seus processos, os quais podem variar de acordo com a importância atribuída ao aspecto ambiental. Ou seja, quanto mais proativa a organização em termos de conceitos ambientais, maior é a sua chance de progredir no mercado (Daroit \& Nascimento, 2000).

Todos esses argumentos mostram que nos países em desenvolvimento, como é o caso do Brasil, a questão ambiental está sendo pouco valorizada em detrimento ao desenvolvimento econômico, ou seja, é possível que as empresas estejam dando menos importância à questão ambiental do que seria o ideal. Assim, a questão norteadora do estudo é: Como as empresas do ramo da prestação de serviços contábeis e de turismo da região da Serra Gaúcha - RS estão conduzindo suas práticas e inciativas ambientais?

A partir dessa pergunta, o presente estudo tem como objetivo analisar as práticas e iniciativas ambientais adotadas em empresas do ramo da prestação de serviços contábeis e de turismo da região da Serra Gaúcha - RS. A Serra Gaúcha está localizada no nordeste do Estado do Rio Grande do Sul e é formada por 33 municípios. A região metropolitana, foco desta pesquisa, é formada por 13 municípios, possuindo mais de 700 mil habitantes (RMSG, 2019).

Estudos sobre práticas e iniciativas ambientais são comuns na literatura. Entretanto, a maioria deles é realizada na indústria (Borges, Rosa, \& Ensslin, 2010; Eckert, Corcini Neto, \& Boff, 2013), sendo em menor número os que envolvem prestação de serviços, como a educação (Tauchen, \& Brandli, 2006) ou laboratórios químicos (Aires, \& Pimenta, 2020). Mas, não se tem conhecimento de outros estudos realizados nas áreas a que se propõe a presente pesquisa.

Além da introdução, este artigo estrutura-se em mais quatro seções, sendo que uma delas aborda a teoria que sustenta a pesquisa. Em seguida são apresentados os aspectos metodológicos utilizados na investigação, a análise e a discussão dos resultados e, por fim, as conclusões do estudo. 


\section{REFERENCIAL TEÓRICO}

\subsection{Preocupação com a questão ambiental}

A preocupação com questões ambientais tem sido trazida à tona nos debates em grandes eventos mundiais. Tanto os países desenvolvidos quanto os em desenvolvimento estão se manifestando sobre a necessidade de se utilizar os recursos naturais de forma mais eficiente e sustentável. Embora tais eventos sejam organizados por diferentes organismos, os mais relevantes são encabeçados pela Organização das Nações Unidas (ONU). O Quadro 1 apresenta um resumo dos principais eventos ocorridos nas últimas décadas.

Quadro 1: Importantes eventos mundiais sobre questões ambientais

\begin{tabular}{|l|l|l|l|}
\hline Ano & Evento & Objetivo & Fonte \\
\hline 1972 & $\begin{array}{l}\text { Conferência de } \\
\text { Estocolmo }\end{array}$ & $\begin{array}{l}\text { Compatibilizar o desenvolvimento com a proteção do meio } \\
\text { ambiente a partir do conceito de “Ecodesenvolvimento". }\end{array}$ & Herrero (2001) \\
\hline 1992 & Rio 92 & $\begin{array}{l}\text { Estabelecer uma série depressupostos quenortearamas ações } \\
\text { deestadosem suas açõesde combate às alteraçõesclimáticas }\end{array}$ & $\begin{array}{l}\text { Feldmann e Furriela } \\
\text { (2001) }\end{array}$ \\
\hline 1997 & $\begin{array}{l}\text { Protocolo de } \\
\text { Kioto }\end{array}$ & $\begin{array}{l}\text { Deliberar que os países desenvolvidossão obrigados a } \\
\text { reduzirsuas emissõescoletivas deseisgases de efeito estufaem } \\
\text { pelo menos 5\% em relação aos níveis de 1990, para o período } \\
\text { entre2008-2012. }\end{array}$ & $\begin{array}{l}\text { Feldmann e Furriela } \\
\text { (2001) }\end{array}$ \\
\hline 2009 & $\begin{array}{l}\text { Copenhagem } \\
\text { COP 15 }\end{array}$ & $\begin{array}{l}\text { Intensificar esforços no sentido de garantir que a temperatura } \\
\text { média do planeta não aumentasse mais de 2 }{ }^{\circ} \text { C. }\end{array}$ & $\begin{array}{l}\text { Gamba e Ribeiro } \\
\text { (2013) }\end{array}$ \\
\hline 2015 & Rio+20 & $\begin{array}{l}\text { Renovar o compromisso mundial com o desenvolvimento } \\
\text { sustentávelatravés dostemas"'economia verdee da erradicação } \\
\text { da pobreza' e 'estrutura institucional do desenvolvimento } \\
\text { sustentável'". }\end{array}$ & Buss et al. (2012) \\
\hline
\end{tabular}

Fonte: Elaborado pelos autores

Moreno e Pol (1999) conceituam a gestão ambiental como sendo aquela que incorpora os valores do desenvolvimento sustentável na organização social e nas metas corporativas da empresa e da administração pública. Essa gestão integra políticas, programas e práticas relativas ao meio ambiente, em um processo contínuo de melhoria. A gestão ambiental se preocupa principalmente com os recursos naturais na medida em que pressupõe escolher alternativas e criar condições para que aconteça de forma mais adequada o que se pretende.

Numa visão mais generalista, a gestão ambiental pode ser definida como o processo de alocação dos recursos naturais de modo a otimizar a sua utilização no atendimento às necessidades humanas básicas, se possível por um período indeterminado e com o mínimo de impactos negativos ao meio ambiente (Martendal et. al., 2013).

Na visão de Tinoco e Robles (2006), a gestão ambiental é um sistema que inclui a estrutura organizacional, as atividades de planejamento, as responsabilidades e as práticas, bem como os procedimentos, processos e recursos para desenvolver, implementar, atingir, analisar criticamente e manter a política ambiental. De forma sucinta, é tudo aquilo que a empresa faz para minimizar ou eliminar os efeitos negativos provocados no ambiente 
na execução de suas atividades. Ainda, segundo os mesmos autores, a gestão ambiental tem se configurado como uma das mais importantes atividades relacionadas a qualquer empreendimento.

As empresas precisam reconhecer que a gestão ambiental desempenha papel específico para a estratégia empresarial e, na mesma medida, colabora para a manutenção dos negócios (Singla, Sethi \& Ahuja (2018). Assim, existem iniciativas ambientais que dizem respeito à sobrevivência da empresa, como é o caso daquelas que visam atender a regulamentações ambientais. Por outro lado, existem iniciativas que favorecem a redução dos custos de operação e dizem respeito à eficiência operacional, como por exemplo, a redução no consumo de água, luz, papel e cartuchos de impressão e o reaproveitamento de materiais sólidos (Santos \& Porto, 2013).

Delmas e Tofell (2004), por sua vez, afirmam que as organizações adotam um conjunto de práticas ambientais distintas porque interpretam as pressões institucionais de formas diferentes. O engajamento nas iniciativas ambientais varia em razão dos diversos níveis de pressão institucional. Entretanto, grande parte dessa variabilidade provém do processo organizacional que traduz as pressões objetivas em pressões percebidas.

O que se verifica é que as principais dificuldades das empresas em gestão ambiental se concentram nas tecnologias de processamento de resíduos, nos custos operacionais e de manutenção dos sistemas de reaproveitamento, de reciclagem e de tratamento. Além disso, ainda que em menor intensidade, destaca-se a legislação, a localização da planta, a pouca cultura ambiental e o treinamento (Silva, Silva, \& Manfrinato, 2005).

Já para Donaire (1999), algumas empresas têm demonstrado que é possível ganhar dinheiro e, ao mesmo tempo, proteger o meio ambiente, mesmo não sendo uma organização atuante no chamado "mercado verde". Para isso, é necessário apenas que estas empresas tenham uma certa dose de criatividade e possuam condições internas para transformar as restrições e ameaças ambientais em oportunidades de negócios.

Hunt e Auster (1990) descrevem cinco estágios, ou fases, no desenvolvimento de programas de gerenciamento ambiental, que se aplicam desde a empresa iniciante, sem nenhuma preocupação ambiental, até a proatividade das empresas altamente comprometidas. O Quadro 2 sintetiza estes estágios:

Quadro 2: Estágios no desenvolvimento de programas de gestão ambiental

\begin{tabular}{|c|l|}
\hline Estágio & \multicolumn{1}{c|}{ Características organizacionais } \\
\hline Primeiro & $\begin{array}{l}\text { Formado por organizações que não possuem programas ambientais, ou possuem programas } \\
\text { limitados por orçamentos ou relações que os tornam impotentes; }\end{array}$ \\
\hline Segundo & $\begin{array}{l}\text { Empresas onde existe um pequeno staff centralizado, que auxilia na resolução das crises } \\
\text { ambientais }\end{array}$ \\
\hline Terceiro & $\begin{array}{l}\text { A organização considera que o máximo a ser feito para o meio ambiente é a prevenção de } \\
\text { acidentes. Não existe efetivamente um programa proativo de gestão ambiental. O que existe é } \\
\text { um departamento ambiental, formado por especialistas como geólogos, químicos ou biólogos, } \\
\text { mas que não possuem influência nem autoridade para fazer mudanças efetivas }\end{array}$ \\
\hline
\end{tabular}




\begin{tabular}{|c|l|}
\hline Quarto & $\begin{array}{l}\text { Empresa que dedicam tempo para gerenciar os problemas ambientais. Os departamentos } \\
\text { ambientais têm experiência, financiamento eautoridade. Avaliam riscos, começam a desenvolver } \\
\text { a educação ambiental, bem como desenvolver programas para treinar os trabalhadores chaves. }\end{array}$ \\
\hline Quinto & $\begin{array}{l}\text { As organizações possuem programas que se estendem por meio da corporação, educam os } \\
\text { funcionários com informações e responsabilidade, monitoram as operações continuamente e } \\
\text { são rápidos em resolver os eventuais problemas. }\end{array}$ \\
\hline
\end{tabular}

Fonte: Adaptado de Hunt e Auster (1990)

Rohrich e Cunha (2004) complementam que as organizações consideradas proativas são aquelas que possuem como diferencial a análise dos possíveis impactos sociais de suas atividades, bem como a divulgação de suas práticas na comunidade. Na sua maioria, essas empresas analisam inclusive o processo de decisão de compra dos consumidores e as possíveis influências dos atributos ambientais.

Fica evidente que todo projeto industrial, desenvolvimento urbano ou oferta de serviço implica na ocorrência de modificações em seu entorno, o que gera um impacto ambiental. Essas mudanças podem ser geridas positivamente, para minimizar seu impacto, ou podem ser ignoradas, deixando que o meio ambiente alterado siga seu curso, normalmente em um processo de degradação cada vez mais acelerado. A forma atual de entender a gestão ambiental remete ao conjunto de ações preventivas e paliativas para minimizar os efeitos ambientais dessa atividade humana. Dessa forma, a gestão ambiental é antes de tudo uma gestão do comportamento humano, tanto dentro quanto fora das organizações (POL, 2003).

Foi para minimizar os impactos ambientais que surgiram as certificações de padrões ambientais internacionais, sendo a primeira a BS 7750, em 1992, seguida pela ISO série 14.000, que teve sua primeira edição em 1994. A proposta de ambos os sistemas é auxiliar as organizações a alcançar os seus objetivos ambientais e econômicos, por meio de compromissos e metas que deverão ser alcançados. A certificação é realizada por uma empresa certificadora independente, o que garante o reconhecimento público do sistema de gestão ambiental implantado (Bispo, \& Cazarini, 2006).

No Brasil, as organizações vêm demonstrando diferentes comportamentos quanto aos aspectos relacionados com a gestão ambiental. Ocorre que muitas vezes, mesmo nos casos em que se observa a existência de um Sistema de Gestão Ambiental certificado, como é o caso da NBR ISO 14.001, há grandes diferenças quando as organizações são analisadas individualmente (Rohrich \& Cunha, 2004).

\subsection{Evidenciação e divulgação das informações ambientais}

Discussões acerca da sustentabilidade do planeta tem proporcionado o aumento da preocupação com a degradação ambiental. Tal fator se reflete nas informações divulgadas pelas organizações, uma vez que as empresas devem informar aos stakeholders sua conduta em relação ao meio ambiente (Lima Filho, Bruni \& Gomes, 2013).

Isso explica a preocupação das empresas em expor a relação entre suas atividades e a utilização dos recursos ambientais, o que vem a ser uma maneira de informar o caráter preventivo e consciente de suas atividades. O objetivo dessa divulgação, dentre outros 
motivos, é reforçar a manutenção de seus clientes e também atrair novos mercados consumidores (Paiva, 2003).

Cada vez mais a sociedade tem cobrado das empresas uma prestação de contas no sentido de identificar aquelas que geram prejuízos ou que não acrescentam nenhum valor à qualidade de vida da comunidade onde estão inseridas. Por este motivo, já não basta mais ter apenas produtos ou serviços de qualidade. Agora, uma das chaves para o sucesso das empresas passa pelas boas práticas ambientais e sociais (Lima Filho, Bruni, \& Gomes, 2013).

Na visão de Cintra (2011), o aumento significativo no volume de divulgação socioambiental nos últimos anos respalda o foco de pesquisas acadêmicas voltadas ao disclosure (evidenciação) ambiental. Nossa (2002) complementa que diversas diretrizes sobre questões ambientais, em especial sobre o disclosure e os relatórios de sustentabilidade, estão sendo desenvolvidas e cita como exemplos o GRI (Global Reporting Initiative), o GEMI (Global Environmental Management Initiative), a Agenda 21, o EMAS (Eco-Management and Audit Scheme), ISAR (Intergovernamental Working Group of Experts on International Standards of Accounting and Reporting), dentre outros.

Muito embora alguns países emitam normas e regulamentações de caráter voluntário e outros de aplicação obrigatória, a maioria das práticas que relatam aspectos ambientais ainda continuam a ser de ordem voluntária (Deegan, 2002). No Brasil, por exemplo, a legislação que regulamenta a elaboração e divulgação das informações contábeis estabelece que sejam mensurados e registrados os passivos ambientais das empresas (Lima Filho, Bruni, \& Gomes, 2013).

Ainda segundo Lima Filho, Bruni e Gomes (2013), normalmente, os passivos ambientais trazem uma conotação negativa, remetendo ao resultado de ações que agrediram significativamente o meio ambiente, e por isso, geraram passivos com valores consideráveis na forma de multas e indenizações a terceiros, para recuperar áreas degradadas ou poluídas. Entretanto, o passivo ambiental também pode ser gerado a partir de atitudes sustentáveis e ambientalmente responsáveis que promovam a execução de medidas preventivas para reduzir impactos ao meio ambiente.

Assim, a mensuração dos gastos de origem de um passivo ambiental pode ser feita em decorrência de um evento ou de uma transação que reflita a interação da organização com o meio ambiente, cujo sacrifício econômico ocorrerá no futuro (Eckert, 2013). Podem ser classificados como passivos ambientais, por exemplo, gastos como aquisição de ativos para contenção de impactos ambientais, pagamento de multas por infrações ambientais e gastos para compensar danos ao meio ambiente (Borba \& Rover, 2006).

Por fim, é importante ressaltar que as iniciativas ambientais adequadamente registradas e divulgadas contribuem para a melhora da reputação da empresa, que é o conjunto de imagens e de percepções que os públicos interno e externo têm a respeito da organização. As empresas buscam maximizar seu prestígio social e, dessa forma, competem pelo reconhecimento dos clientes, investidores, empregados, comunidade 
e até concorrentes. Uma boa reputação organizacional cria um obstáculo de natureza intangível difícil de ser transposto, de forma que para ser duradoura e resiliente, depende de investimentos no relacionamento com todos os stakeholders (Fombrun, 1996).

\subsection{Práticas ambientais em escritórios contábeis e empresas de turismo}

Marion e Santos (2001) afirmam que os escritórios contábeis são organizações nas quais atuam os profissionais contábeis, tendo a função de registrar os dados dos seus clientes, atuam como "tradutores" das informações contábeis. Com um mercado que exige cada vez mais competência, existe uma grande necessidade acerca da confiabilidade e agilidade dessas informações.

Os escritórios especializados na prestação de serviços contábeis precisam conciliar o grande fluxo de informações de seus diversos clientes, mantendo a capacidade para realizar sua proposta básica de forma satisfatória. Além disso, diante da competitividade do mercado, estes profissionais precisam não somente manter a qualidade em seus serviços, mas também apresentar um diferencial (Caneca et al., 2009).

Já as empresas prestadoras de serviços de turismo, como explica Tomazzoni (2006), são outro exemplo de negócios que fomentam a produção e o mercado. Especialmente na região da Serra Gaúcha, o turismo encontra-se diretamente ligado com as principais fontes de recursos dos municípios. Segundo Keller (2011), a cultura, a gastronomia e a geografia da Serra Gaúcha contribuem para o turismo da região que se consolida cada vez mais com os investimentos voltados para manter esta tradição.

Assim como qualquer negócio em expansão e em constante mudança, existe a necessidade de adequação e preocupação com o meio ambiente, não só voltado para os turistas, na prática do chamado "ecoturismo", mas também a todos os colaboradores, usuários e demais envolvidos. Afinal, como afirma Ramos (2004), as políticas ambientais não devem ser vistas como inibidores do turismo, mas sim como propulsores da atividade e um diferencial para as empresas do ramo.

\section{ASPECTOS METODOLÓGICOS}

\subsection{Delineamento da pesquisa}

Quanto aos objetivos, o método empregado nesta pesquisa é de natureza descritiva. Cooper e Schindler (2003) afirmam que ela é utilizada quando se deseja descrever o comportamento de fenômenos ou de características da população alvo, mensurando e/ou quantificando os eventos. Para Barros e Lehfeld (2007), neste tipo de pesquisa não há a interferência do pesquisador, cabendo a ele apenas descrever o objeto da pesquisa, bem como descobrir a frequência com que determinado fenômeno ocorre, suas características, natureza, causas, relações e conexões com outros fenômenos.

Em relação aos procedimentos técnicos, foi realizado um levantamento, dito também survey. De acordo com May (2004), a survey se caracteriza pela coleta de dados referentes 
a um grande número de pessoas e visa descrever ou explicar as características de uma população através da utilização de uma amostra representativa. Quanto à forma de abordagem, este estudo contempla as características de uma pesquisa predominantemente quantitativa, explicada por Oliveira (2011) como aquelas que traduzem em números as opiniões coletadas, para classificá-las e analisá-las. Segundo Richardson (1989), as pesquisas quantitativas empregam um instrumental estatístico tendo por base o processo de análise do problema, objetivando medir unidades ou categorias homogêneas.

\subsection{Procedimentos de coleta e análise dos dados}

A pesquisa foi realizada mediante a aplicação de um questionário, encaminhado através de correio eletrônico, composto por vinte e uma questões de múltipla escolha, e por uma questão final, aberta. As questões iniciais (1 a 18) foram elaboradas com base nas sugestões de iniciativas e práticas ambientais nas empresas da publicação "Indicadores Ethos para Negócios Sustentáveis e Responsáveis" (Ethos, 2016). As questões deste primeiro bloco eram compostas por uma escala do tipo Likert, variando de 1 (discordo totalmente) até 7 (concordo totalmente).

É importante ressaltar que o Instituto Ethos de Empresas e Responsabilidade Social é uma Oscip (Organização da Sociedade Civil de Interesse Público), que busca mobilizar, sensibilizar e ajudar as empresas a gerir seus negócios de forma socialmente responsável, tornando-as parceiras na construção de uma sociedade justa e sustentável. Dentre as atividades desenvolvidas, destaca-se a publicação dos Indicadores Ethos para Negócios Sustentáveis e Responsáveis. Trata-se de uma ferramenta de gestão, gratuita, que visa apoiar as empresas na incorporação da sustentabilidade e da responsabilidade social empresarial (RSE) em suas estratégias de negócio, de modo que esse venha a ser sustentável e responsável. Estes indicadores têm como foco avaliar o quanto a sustentabilidade e a responsabilidade social têm sido incorporadas aos seus negócios, auxiliando na definição de estratégias, políticas e processos (ETHOS, 2016).

As questões seguintes (19 a 21), também de múltipla escolha, buscaram identificar o perfil da empresa respondente, mais especificamente em relação à cidade em que se localiza a empresa, sobre a quantidade de empregados e sobre a participação em programas de gestão ambiental. Por fim, a questão 22 permitia que o respondente fizesse alguma consideração adicional, tanto em relação ao questionário, quanto sobre a sua empresa ou sobre as respostas das questões anteriores.

O questionário foi elaborado na ferramenta Google Forms e distribuído eletronicamente para um grupo de escritórios de contabilidade e empresas de turismo situados na Região metropolitana da Serra Gaúcha. Esta amostra foi estabelecida por conveniência, pelo fato de dos contatos serem escolhidos em listagens de fácil acesso, como sites de sindicatos e associações, o que facilitou a distribuição dos instrumentos. Os questionários foram enviados para aproximadamente de 200 escritórios de contabilidade, retornando 76 questionários preenchidos. Já para as empresas de turismo foram enviados aproximadamente 80 
questionários, retornando 32 completamente preenchidos. Portanto, dos 280 questionários enviados, retornaram 108 respondidos, o que equivale a um percentual aproximado de $38 \%$.

A partir dos questionários respondidos, procedeu-se a tabulação das respostas no software IBM SPSS Statistics $21 \circledR$, o qual disponibiliza diversos recursos estatísticos que auxiliam na análise dos resultados.

\section{ANÁLISE E DISCUSSÃO DOS RESULTADOS}

\subsection{Perfil da amostra pesquisada}

Tendo por base as respostas obtidas, o Quadro 3 apresenta o perfil das empresas que participaram da pesquisa, identificado a partir do agrupamento de três questões (19 a 21). Na primeira delas, foi solicitado que os respondentes indicassem em qual cidade situava-se a sua empresa. Conforme pode ser verificado no Quadro 3, a grande maioria das empresas participantes da pesquisa são da cidade de Caxias do Sul, 62 de um total de 108, o equivalente a $57,4 \%$ do total, seguida por Flores da Cunha com 9 questionários respondidos e $9,3 \%$ do total, enquanto $33,3 \%$ são de outras cidades da Região.

\begin{tabular}{|c|c|c|c|c|}
\hline Cidade & Frequência & Percentual & $\begin{array}{l}\text { Percentual } \\
\text { válido }\end{array}$ & $\begin{array}{l}\text { Percentual } \\
\text { acumulado }\end{array}$ \\
\hline $\begin{array}{l}\text { Caxias do Sul } \\
\text { Flores da Cunha } \\
\text { Bento Gonçalves } \\
\text { Gramado } \\
\text { Farroupilha } \\
\text { São Francisco de } \\
\text { Paula } \\
\text { Nova Petrópolis } \\
\text { São Marcos } \\
\text { Antônio Prado } \\
\text { Bom Jesus } \\
\text { Garibaldi } \\
\text { São Jose dos } \\
\text { Ausentes } \\
\text { Vacaria } \\
\text { Total }\end{array}$ & $\begin{array}{c}62 \\
10 \\
8 \\
8 \\
6 \\
4 \\
3 \\
2 \\
1 \\
1 \\
1 \\
1 \\
1 \\
108\end{array}$ & $\begin{array}{c}57,4 \\
9,3 \\
7,4 \\
7,4 \\
5,6 \\
3,7 \\
2,8 \\
1,9 \\
0,9 \\
0,9 \\
0,9 \\
0,9 \\
0,9 \\
100,0\end{array}$ & $\begin{array}{c}57,4 \\
9,3 \\
7,4 \\
7,4 \\
5,6 \\
3,7 \\
2,8 \\
1,9 \\
0,9 \\
0,9 \\
0,9 \\
0,9 \\
0,9 \\
100,0\end{array}$ & $\begin{array}{c}66,7 \\
81,5 \\
8,3 \\
89,8 \\
72,2 \\
96,3 \\
92,6 \\
99,1 \\
, 9 \\
9,3 \\
82,4 \\
97,2 \\
100,0\end{array}$ \\
\hline
\end{tabular}

Destaca-se o fato de que $79,20 \%$ das empresas estão dentro dessa área chamada região metropolitana da Serra Gaúcha. Embora outros municípios também tenham empresas que necessitem de serviços contábeis e tenham pontos turísticos, a região metropolitana tem uma densidade populacional maior e consecutivamente concentra mais empresas destes ramos. 
A questão seguinte, a número 20, buscava identificar o porte da empresa. Embora existam diversas maneiras de mensurar o tamanho da empresa, como por exemplo, faturamento e área construída, optou-se em questionar sobre a quantidade de funcionários (Sebrae, 2020), visto que esta seria uma informação que todos teriam condições de responder, independente do seu posicionamento dentro da organização.

Desta forma ficou claro que mais da metade $(53,7 \%)$ das empresas tem menos de 10 funcionários, e que $85,2 \%$ possuem menos de 50 funcionários. Chama atenção que apenas 9 empresas entrevistadas têm mais de 100 funcionários, representando apenas $8,3 \%$. 0 Quadro 4 apresenta estes resultados.

Quadro 4: Quantidade de empregados

\begin{tabular}{|c|c|c|c|c|}
\hline Quantidade & Frequência & Percentual & $\begin{array}{c}\text { Percentual } \\
\text { válido }\end{array}$ & $\begin{array}{c}\text { Percentual } \\
\text { acumulado }\end{array}$ \\
\hline Até 10 & 58 & 53,7 & 53,7 & 53,7 \\
De 11 a 20 & 22 & 20,4 & 20,4 & 74,1 \\
De 21 a 50 & 12 & 11,1 & 11,1 & 85,2 \\
De 51 a 100 & 7 & 6,5 & 6,5 & 91,7 \\
Mais de 100 & 9 & 8,3 & 8,3 & 100,0 \\
Total & 108 & 100,0 & 100,0 & \\
\hline
\end{tabular}

A pesquisa revela que poucos escritórios contábeis e empresas de turismo são de grande porte. A maioria mantém menos de 10 funcionários no seu ambiente de trabalho, indicando que essas empresas preferem manter seus negócios pequenos e/ou não tem muita demanda de serviços do ramo no município em que se encontram.

A última questão relacionada ao perfil da empresa, questão 21 , estava voltada a descobrir se as empresas participantes da pesquisa possuíam algum tipo de programa de gestão de qualidade ativo na empresa, tendo somente duas possibilidades de respostas para essa pergunta: positiva ou negativa.

De acordo com as informações apresentadas no Quadro 5, dentre as empresas pesquisadas, 68 não possuem um sistema de qualidade implantado representando $63 \%$ das empresas pesquisadas.

Quadro 5: Programa de gestão da qualidade implantado

\begin{tabular}{|c|c|c|c|c|}
\hline $\begin{array}{c}\text { Sistema de } \\
\text { qualidade }\end{array}$ & Frequência & Percentual & $\begin{array}{c}\text { Percentual } \\
\text { válido }\end{array}$ & $\begin{array}{c}\text { Percentual } \\
\text { acumulado }\end{array}$ \\
\hline Não & 68 & 63,0 & 63,0 & 63,0 \\
Sim & 40 & 37,0 & 37,0 & 100,0 \\
Total & 108 & 100,0 & 100,0 & \\
\hline
\end{tabular}

O sistema da gestão da qualidade coloca em prática estratégias que visam otimizar os processos, reduzir custos e melhorar a qualidade de cada etapa das atividades empresariais. Logo, pode-se afirmar que a maioria das empresas entrevistadas está desconsiderando os 
benefícios da implantação deste sistema.

Encerradas as tabulações e as análises acerca do perfil das empresas, parte-se para a identificação e a análise das iniciativas e práticas ambientais dessas empresas, que serão analisadas no tópico a seguir. Como já visto no tópico da metodologia, para atingir este objetivo, foram elaboradas 18 questões, cujas alternativas consistiam em uma escala do tipo Likert de 7 pontos. Para facilitar a análise, as questões foram agrupadas de acordo com o enfoque das mesmas.

\subsection{Adaptação às Mudanças Climáticas}

As duas primeiras questões (1 e 2) referiram-se ao conhecimento, por parte da empresa, acerca dos impactos causados pelas mudanças climáticas, tanto no seu negócio, como no setor ou região em que atua. As respostas resumidas estão apresentadas no Quadro 6.

Quadro 6: Conhecimento sobre impactos das mudanças climáticas

\begin{tabular}{|c|c|c|}
\hline & $\begin{array}{c}\text { Q1:A empresa busca conhecer os } \\
\text { possíveis impactos das mudanças } \\
\text { climáticas para seu negócio. }\end{array}$ & $\begin{array}{c}\text { Q2: A empresa possui conhecimento relativo } \\
\text { aos impactos das mudanças climáticas sobre } \\
\text { o setor ou região em que atua. }\end{array}$ \\
Média & 3,95 & 3,93 \\
Desvio Padrão & 1,926 & 1,878 \\
Mínimo & 1 & 1 \\
Máximo & 7 & 7 \\
\hline
\end{tabular}

Percebe-se que em ambas a questões as respostas são parecidas, ambas demonstram uma preocupação não muito relevante com os impactos das atividades no meio ambiente, as respostas mostram uma média de 3,95 e 3,93 nas empresas participantes da pesquisa. Porém, o que mais chama atenção é que nas duas perguntas a opção mais marcada foi a que representava que a empresa respondente "discordava totalmente", ou seja, que não tem ou não buscam ter conhecimento dos impactos de suas atividades, ou de seu setor nas mudanças climáticas.

Interessante nessas respostas é que, possivelmente um dos motivos para este resultado pode ser proveniente da ideia errônea que as empresas têm de que o fator climático está muito distante da sua realidade, ou seja, por não interferir diretamente no andamento de seus negócios não merece atenção primordial.

\subsection{Sistema de Gestão Ambiental}

Naime et al. (2011) atribuem a gestão ambiental como estratégia de competitividade no mercado. Já Souza (2002) afirma que, além disso, as empresas buscam a gestão ambiental para melhorar a imagem do seu negócio, por pressão da concorrência ou até mesmo pela imposição da legislação vigente.

A respeito disso, a terceira pergunta questionava as empresas se elas participavam ativamente de iniciativas ambientais, referindo-se à aplicação do sistema de gestão 
ambiental. Conforme o que mostra o Quadro 7, as respostas foram regulares, demonstrado pela média de 3,40 nessa questão. Percebe-se que as empresas entrevistadas não mantêm um vínculo direto com atividades ambientais, mesmo considerando que a amostra é composta, em parte, de empresas do ramo turístico, que muitas vezes se encontram ligadas ao ecoturismo (turismo sustentável).

Quadro 7: Engajamento em aspectos ambientais

\begin{tabular}{|l|c|c|c|}
\hline & $\begin{array}{c}\text { Q3:Participa ativamente } \\
\text { de iniciativas ambientais. }\end{array}$ & $\begin{array}{c}\text { Q4: Busca as iniciativas } \\
\text { do poder público. }\end{array}$ & $\begin{array}{c}\text { Q5: Adequa-se } \\
\text { rapidamente a novos } \\
\text { acordos e regras. }\end{array}$ \\
\hline Média & 3,40 & 3,25 & 4,01 \\
Desvio Padrão & 2,009 & 1,741 & 1,837 \\
Mínimo & 1 & 1 & 1 \\
Máximo & 7 & 7 & 7 \\
\hline
\end{tabular}

Na pergunta de número 4 , os respondentes foram questionados com a seguinte pergunta: "A empresa busca as iniciativas do poder público que estão relacionadas à sua estratégia?". A média neste item atingiu 3,25, demonstrando que ainda existe uma lacuna entre as empresas e os órgãos públicos, falta de esclarecimento, comunicação até de conhecimento por parte das empresas em relação às ferramentas que pode utilizar em sua estratégia.

A quinta pergunta a ser respondida questionava se a empresa agia com celeridade e adequava-se rapidamente a novos acordos e regras ambientais, quando estas entravam em vigor. De acordo com o Quadro 7, as respostas dessa questão tiveram uma média mais alta se comparada as questões anteriores deste enfoque, 4,01 foi a média alcançada no questionamento sobre a rápida adequação as novas normas e legislações ambientais.

Mesmo com respostas positivas, essa questão revela que as empresas tendem a cumprir as regras ambientais quando as mesmas se tornam, de certo modo, compulsórias. A iniciativa própria das práticas ambientais não é usual entre as empresas pesquisadas.

\subsection{Prevenção da Poluição}

As três questões seguintes, por sua vez, visavam reunir informações acerca de aspectos relativos à poluição. As duas primeiras remetiam à prevenção da poluição na empresa, e a última, à comunicação existente entre a empresa e a comunidade. O Quadro 8 apresenta uma síntese das respostas obtidas. 
Quadro 8: Aspectos relativos à poluição

\begin{tabular}{|l|c|c|c|}
\hline & $\begin{array}{c}\text { Q6: A empresa possui } \\
\text { iniciativas ou ações de } \\
\text { prevenção à poluição } \\
\text { com foco nos 3Rs: reduzir, } \\
\text { reutilizar e reciclar, ou } \\
\text { semelhante. }\end{array}$ & $\begin{array}{c}\text { Q7: A empresa realiza } \\
\text { campanhas internas } \\
\text { visando capacitar } \\
\text { seus empregados em } \\
\text { relação à poluição e sua } \\
\text { prevenção. }\end{array}$ & $\begin{array}{c}\text { Q8: A empresa possui um } \\
\text { canal de comunicação } \\
\text { informal para a comunidade } \\
\text { com relação a questões } \\
\text { de ruídos, poeira, odores e } \\
\text { outros. }\end{array}$ \\
\hline $\begin{array}{l}\text { Média } \\
\text { Desvio }\end{array}$ & 4,77 & 3,88 & 2,98 \\
Mánimo & 1,907 & 2,003 & 1,899 \\
Máximo & 1 & 1 & 1 \\
\hline
\end{tabular}

Layarargues (2002) explica a pedagogia dos 3Rs como uma ideologia de preservação e desaceleração dos danos ao meio ambiente, onde a prioridade é a redução do consumo, reutilização dos materiais (o que diminui o lixo e a poluição) e, por fim, a reciclagem que auxilia no aumento da vida útil destes materiais, evitando o desperdício.

Em resposta às questões 6 e 7, que analisa justamente as políticas de prevenção da poluição, as empresas exibiram um perfil introspectivo, onde há uma preocupação maior em direcionar seus funcionários à educação ambiental, porém esta consciência se limita ao ambiente de trabalho, pois, conforme resultado da questão 8, praticamente não existe a comunicação com a comunidade a respeito deste assunto.

\subsection{Uso Sustentável de Recursos: Materiais}

A questão de número 9 indagava: "A empresa realiza campanhas com empregados, por exemplo, redução de impressões, reutilização dos copos descartáveis e outros, visando à redução do consumo de materiais?". Neste item as respostas foram mais positivas que as anteriores, tendo uma pontuação média de 4,70 como nos mostra o Quadro 9.

Quadro 9: Uso sustentável de recursos materiais

\begin{tabular}{|l|c|c|}
\hline & $\begin{array}{c}\text { Q9: A empresa realiza campanhas com } \\
\text { empregados, por exemplo, redução de } \\
\text { impressões, reutilização dos copos descartáveis, } \\
\text { entre outros, visando à diminuição do consumo } \\
\text { de materiais. }\end{array}$ & $\begin{array}{c}\text { Q10: A empresa realiza coleta seletiva } \\
\text { em algumas unidades ou áreas da } \\
\text { organização, por exemplo, na área } \\
\text { administrativa. }\end{array}$ \\
\hline Média & 4,70 & 5,10 \\
Desvio Padrão & 1,954 & 2,009 \\
Mínimo & 1 & 1 \\
Máximo & 7 & 7 \\
\hline
\end{tabular}

Esta questão demonstra que mesmo as empresas não possuindo um sistema de gestão de qualidade voltado para as questões ambientais, elas têm uma preocupação em relação à redução de consumo de descartáveis e de papeis. O principal motivo pode estar diretamente ligado com a questão financeira, pois estas atitudes implicam na redução de custos para a empresa. 
Um dos conceitos básicos da preservação ambiental é a separação, coleta e destinação correta de resíduos. Dentre as empresas pesquisadas, as respostas à questão 10 apontaram alta consciência e responsabilidade ambiental neste quesito, ou seja, a maioria das empresas realiza coleta seletiva nas unidades ou áreas da organização.

\subsection{Uso Sustentável de Recursos: Água}

A redução do consumo de água era o foco das questões 11 e 12. A primeira delas perguntava se a empresa costuma realizar campanhas com empregados que visam à diminuição no consumo de água, e a outra, se a empresa realiza ações em algumas de suas unidades/áreas, como por exemplo, na área administrativa, instalando torneiras com temporizadores, dentre outros.

A questão 11 apresentou uma média de 4,19, uma resposta positiva em relação às campanhas voltadas a funcionários para diminuir o consumo de água. Já a questão 12 resultou em uma média menor de 3,37, indicando que nas empresas pesquisadas existe pouca intenção de promover campanhas para o consumo consciente de água.

Quadro 10: Redução no consumo de água

Q11: A empresa realiza campanhas com empregados que visam à diminuição no consumo de água.

\begin{tabular}{|l|}
\hline \\
\hline Média \\
Desvio Padrão \\
Mínimo \\
Máximo \\
\hline
\end{tabular}

Q12: A empresa realiza ações em algumas unidades/ áreas da organização - na área administrativa, por exemplo -, como uso de torneiras com temporizadores, entre outras.

3,37

2,094

1

7

De modo geral, em relação às campanhas de diminuição do desperdício de água, as empresas realizam o básico, incentivando os empregados a manter os bons hábitos de consumo. Por outro lado, as entrevistadas não investem em alternativas práticas que diminuem o consumo de água e pouco promovem ações de conscientização dentro das unidades e áreas da organização, ou seja, mesmo que isso represente um benefício ou redução de custo futuro, não existe uma preocupação relevante neste ponto.

\subsection{Uso Sustentável de Recursos: Energia}

As questões 13 e 14, por sua vez, indagavam acerca da redução do consumo de energia na empresa. Elas questionavam se a empresa desenvolve campanhas com empregados no sentido de reduzir o consumo de energia, e se realiza ações em algumas de suas unidades/áreas com o objetivo de reconhecer oportunidades de redução de consumo de energia.

Conforme pode ser visto no Quadro 11, as empresas desenvolvem campanhas internas visando a redução do consumo de energia, porém nem todos os que responderam positivamente a esta questão confirmaram que seus escritórios realizam efetivamente ações neste sentido. 
Quadro 11: Redução no consumo de energia

\begin{tabular}{|l|c|c|}
\hline & $\begin{array}{c}\text { Q13: A empresa desenvolve campanhas } \\
\text { com empregados visando a redução do } \\
\text { consumo de energia. }\end{array}$ & $\begin{array}{c}\text { Q14: A empresa realiza ações em algumas } \\
\text { unidades/áreas da organização com o } \\
\text { objetivo de reconhecer oportunidades de } \\
\text { redução do consumo de energia. }\end{array}$ \\
\hline $\begin{array}{l}\text { Média } \\
\text { Desvio }\end{array}$ & 4,46 & 3,97 \\
Máníno & 2,071 & 2,011 \\
Máximo & 1 & 1 \\
\hline
\end{tabular}

Assim como ocorreu na pesquisa sobre o consumo da água, as empresas tendem a incentivar os funcionários em relação à redução do consumo da energia elétrica, porém as ações e campanhas para redução do consumo não são tão fortes. Essas avaliações estão ligadas à proatividade das empresas e percebe-se, neste contexto, que existe pouco interesse em se fazer além do básico, demonstrando que estas organizações poderiam ser mais comprometidas com essa questão.

Como uma curiosidade, as respostas da Questão 13 foram as mais equilibradas da pesquisa, todas as opções disponibilizadas receberam de 9 a 13 votos cada. Isso indica que as empresas entrevistadas pouco diferem a sua opinião acerca de campanhas de redução de consumo da energia elétrica, estabelecendo uma semelhança de hábitos e conduta dentro do seu ambiente de trabalho.

\subsection{Educação e Conscientização Ambiental}

As duas questões seguintes eram direcionadas às iniciativas ambientais das empresas para com seus empregados. Na pergunta 15, foi questionado se a empresa promove treinamento aos empregados sobre educação ambiental, buscando maior engajamento e conscientização do público interno.

Neste item, foi identificado que a maior parte das empresas não promove nenhum tipo de treinamento pontual para seus colaboradores sobre o tema, afirmação comprovada no Quadro 12, onde $40 \%$ das empresas responderam que discordam totalmente (não possuem) e apenas 1,3\% que concordam totalmente (possuem).

A outra questão relativa ao envolvimento dos empregados com as questões ambientais era a seguinte: "A empresa possui programas contínuos de capacitação dos empregados no tema da questão ambiental?" Segundo os resultados na Questão 16, mais de $45 \%$ das empresas não possuem nenhum programa de capacitação continua para os colaboradores. 
Quadro 12: Redução no consumo de energia

\begin{tabular}{|l|c|c|}
\hline & $\begin{array}{c}\text { Q15: A empresa promove treinamento pontuais aos } \\
\text { empregados sobre educação ambiental, buscando } \\
\text { maior engajamento e conscientização do público } \\
\text { interno. }\end{array}$ & $\begin{array}{c}\text { Q16: A empresa possui } \\
\text { programas contínuos de } \\
\text { capacitação dos empregados no } \\
\text { tema. }\end{array}$ \\
\hline $\begin{array}{l}\text { Média } \\
\text { Desvio }\end{array}$ & 3,02 & 2,77 \\
Padrão & 2,014 & 1,853 \\
Mínimo & 1 & 1 \\
Máximo & 7 & 6 \\
\hline
\end{tabular}

Ambas as questões apresentam médias baixas e revelam a omissão por parte das empresas em relação à educação ambiental que em tese deveria ser fornecida aos funcionários e solidificada como um processo comum no ambiente de trabalho. Jacobi (2003) confirma essa importância ao afirmar que a educação ambiental serve não só para tornar os indivíduos responsáveis pelo meio ambiente, mas também transformar todas as atividades do negócio numa relação de desenvolvimento sustentável.

\subsection{Logística Reversa}

A décima sétima pergunta do questionário buscava identificar se a empresa já mapeou e/ou contatou parceiros para destinar seus resíduos de produtos, como cooperativas de catadores ou outras empresas de processamento de resíduos, e se já identificou a necessidade para desenvolver essas parcerias.

\section{Quadro 13: A logística reversa}

\begin{tabular}{|l|c|c|}
\hline \multirow{1}{*}{} & $\begin{array}{c}\text { Q17: A empresa mapeou e/ou contratou } \\
\text { parceiros para destinar seus resíduos } \\
\text { de produtos, como cooperativas de } \\
\text { catadores ou outras empresas de } \\
\text { processamento de resíduos/partes } \\
\text { usadas, e já identificou a necessidade de } \\
\text { desenvolver esses parceiros. }\end{array}$ & $\begin{array}{c}\text { Q18: A empresa participa ativamente } \\
\text { de reuniões ou grupos de trabalho no } \\
\text { nível setorial ou nas diferentes esferas } \\
\text { políticas que tratam do tema (destinação } \\
\text { de seus resíduos) e buscam soluções } \\
\text { práticas para o setor. }\end{array}$ \\
\hline Média & 3,20 & 2,72 \\
Mesvio Padrão & 2,169 & 1,808 \\
Máximo & 1 & 1 \\
\hline
\end{tabular}

Percebe-se, conforme apresentado no Quadro 13, a relutância da maioria das empresas em aderir esta atividade sustentável. A logística reversa é um assunto muito comentado atualmente e consiste em um conjunto de ações que prevê o reaproveitamento ou descarte apropriado de materiais. Nagan, Merlo e Braga Junior (2009) afirmam que este processo visa a materialização da sustentabilidade, como um serviço em favor ao meio ambiente, ao mesmo tempo em que eleva a reputação das organizações à um patamar diferenciado e gera benefícios econômicos em toda a sua abrangência. 
Por fim, a última pergunta do questionário era: "A empresa participa ativamente em reuniões ou grupos de trabalho no nível setorial ou nas diferentes esferas políticas que tratam do tema e buscam soluções práticas para o setor?" Nesta questão foi obtida a maior quantidade de respostas negativas da pesquisa, e consequentemente a menor média, com 2,72. Podese perceber que as empresas entrevistadas não participam de reuniões ou encontros para a discussão trabalhada, em busca de práticas ou sistemas que auxiliariam na busca de um processo mais sustentável nas empresas.

O questionário disponibilizava um espaço para as empresas inserirem considerações. Por se tratar, em sua maioria, de empresas de pequeno porte, alguns respondentes acharam relevante informar que são enquadrados no regime $\mathrm{MEl}$ e que basearam suas respostas em suas próprias ações. Outra empresa afirmou que se preocupa com a separação e destinação correta dos resíduos e reutilização dos papeis, cujo descarte e feito por meio de empresa especializada. E por fim, outra empresa destacou que a gestão da qualidade fica a cargo de um responsável técnico.

\section{CONCLUSÕES}

Diante do exposto, cada vez com maior ênfase, a sociedade necessita estar consciente de que a utilização dos recursos naturais de maneira inadequada acelera a degradação do meio ambiente, por isso o poder público, as organizações não governamentais e empresas devem buscar práticas de gestão ambiental que permitam interferir o menos possível na qualidade dos recursos naturais. No presente estudo procurou-se analisar as práticas e iniciativas ambientais de um grupo de escritórios contábeis e empresas de turismo na Serra Gaúcha, no Rio Grande do Sul.

Para atingir o objetivo da pesquisa, realizou-se uma survey com um questionário de múltipla escolha baseado no relatório "Indicadores Ethos para Negócios Sustentáveis e Responsáveis", que é uma ferramenta de gestão que busca apoiar as empresas na incorporação da sustentabilidade e da responsabilidade social empresarial nas estratégias de negócio, de modo que essa venha a ser sustentável e responsável (Ethos, 2016).

Os resultados obtidos na pesquisa demonstram que embora seja um assunto de suma importância, nem todas as empresas participantes da pesquisa buscam conhecer os impactos que seu negócio, ou que seu setor sofre com as mudanças climáticas. Essas informações geram certo nível de preocupação, pois o primeiro passo para termos iniciativas e campanhas buscando uma gestão ambiental nas empresas, é o conhecimento dos possíveis impactos que podem afetar seus negócios.

É perceptível, ainda, que a maioria das empresas não participa ativamente de iniciativas ambientais e nem buscam iniciativas do poder publico relacionados ao assunto. Agora quando se trata respeitar novos acordos e regras implantadas as empresas se mostram mais receptivas o que nos trás a indicação de que se adéquam rapidamente as mudanças. 
Em se tratando de poluição ambiental, percebe-se que a maioria das empresas possui iniciativas internas para a prevenção da poluição, porém grande parte não possui campanhas visando capacitar seus colaboradores em relação a isso e nem possuem canais de comunicação com a comunidade. O que desfavorece as empresas que praticam campanhas de prevenção a poluição, pois a informação de tal prática a comunidade Ihe traria mais credibilidade no mercado que atua devido a importância que comunicabilidade possui no nosso cotidiano atualmente.

Os resultados indicam que as empresas participantes da pesquisa demonstram ter preocupação com a redução de consumo de matérias, através de práticas como a redução de impressões, reutilização de papeis nas impressões, redução no uso de copos descartáveis, e também fazem coleta seletiva em alguma das áreas da empresa. Porém, algo que precisa de mais atenção nas empresas é o consumo despreocupado de água, não havendo campanhas na maioria das empresas para conscientização no consumo, ou ações na tentativa de reduzir desperdícios, tais como torneiras com temporizadores.

Já quando se fala no consumo de energia elétrica existe uma conscientização maior em relação ao consumo racional e também como podem ser realizadas ações para oportunizar a redução no consumo. Ainda não se pode dizer que os números são considerados bons, pois essas práticas deviam ser constantes nas empresas, já que além de gerar impactos ambientais elas também podem gerar gastos desnecessários para as empresas devido ao consumo inconsciente.

Outro ponto que ficou evidente no estudo é a falta de treinamentos e/ou programas de capacitação para os funcionários no tema. O que seria de ótima utilidade, pois a educação ambiental contribuiria muita na conscientização e criaria uma rotina própria no funcionário de se questionar se seus atos e ações estão de algum modo contribuindo para a situação climática atual.

O estudo também nos trouxe o conhecimento que grande parcela das empresas nunca mapeou e/ou contratou empresas especializadas para destinação de resíduos, nem identificou a necessidade desse tipo de procedimento nos escritórios. $E$ também, as empresas não participam significantemente de reuniões ou grupo de trabalho, a níveis setoriais ou não, para buscar alternativas e/ou soluções práticas para o setor em relação ao tema pesquisado.

Quanto às limitações deste estudo, vale lembrar que a pesquisa foi respondida por proprietário ou funcionários que atuam nas empresas participantes, gerando a possibilidade de distorção nas informações devido a corresponderem a diversos pontos de vista. Se a pesquisa fosse direcionada a um setor em específico ou aos gestores da empresa, as respostas poderiam ser diferentes. $E$ também devido ao fato das respostas serem referentes ao grupo de empresas participantes da pesquisa, que correspondem a uma amostra do setor em questão, não se pode fazer interferências em empresas que não participaram do estudo. Ou seja, como se trata de uma pesquisa não-probabilística, não é possível generalizar os resultados. 
Como sugestões de pesquisas futuras, poderia-se utilizar este instrumento em outras regiões do país ou, inclusive, fora dele, e depois comparar os resultados. Ainda, poderia-se realizar uma pesquisa na mesma região, porém valendo-se de outro instrumento de pesquisa, ou outros procedimentos metodológicos, a fim de estabelecer relações comparativas entre os resultados.

\section{REFERÊNCIAS}

Alves, J. E. D. (2015). Os 70 anos da ONU e a agenda global para o segundo quinquênio (2015-2030)do séculoXXI. Revista Brasileira de Estudos de População, 32(3). Disponível em: $\quad$ <http://www.scielo.br/scielo.php?pid=S0102-30982015000300587\&script=sci_ arttext\&tlng=en>

Aires, C. F., \& Pimenta, H. C. D. (2020). Práticas ambientais em laboratórios químicos universitários: uma revisão sistemática de literatura. Research, Society and Development, 9(8), 378-398.

Bachmann, R. K. B., Carneiro, L. M., \& Espejo M. M.S. B. (2013). Evidenciação de informações ambientais: proposta de um indicador a partir da percepção de especialistas. Revista de Contabilidade e Organizações. 17(1), 36-47

Barros, A., \& Lehfeld, N. A. S. (2007). Fundamentos de Metodologia Científica. 3. ed. São Paulo: Pearson Prentice Hall

Bispo, C. A. F., \& Cazarini, E. W. (2006). Avaliação qualitativa paraconsistente do processo de implantação de um sistema de gestão ambiental. Revista Gestão e Produção, 13(1), 117-127.

Borba, J. A., \& Rover, S. (2006) A evidenciação das informações ambientais nas demonstrações contábeis das empresas que atuam no Brasil e que negociam na bolsa de valores dos Estados Unidos: Uma análise das DFP's (CVM) e do relatório 20-F (SEC). Congresso USP de Contabilidade e Controladoria. São Paulo

Borges, A. P., Rosa, F. S. D., \& Ensslin, S. R. (2010). Evidenciação voluntária das práticas ambientais: um estudo nas grandes empresas brasileiras de papel e celulose. Production, 20(3), 404-417.

Buss, Paulo Marchiori; Machado; Jorge Mesquita Huet; Gallo, Edmundo; Magalhães, Danielly de Paiva; Setti, Andréia Faraoni Freitas; Netto, Francisco de Abreu Franco; Buss \& Daniel Forsin. (2012). Governança em saúde e ambiente para o desenvolvimento sustentável. Ciência \& Saúde Coletiva, 17(6):1479-1491.

Caneca, Roberta Lira; Miranda, Luiz; Rodrigues, Raimundo Nonato; Libonati, Jeronymo José; Freire \& Deivisson Rattacaso. (2009). A Influência da Oferta de Contabilidade Gerencial na Percepção da Qualidade dos Serviços Contábeis Prestados aos Gestores de Micro, Pequenas e Médias Empresas. Pensar Contábil, 11(43). 123-145. 
Cintra, Y. C. (2011). A integração da sustentabilidade às práticas de controle gerencial das empresas no Brasil. Tese Doutorado em Controladoria e Contabilidade. Universidade de São Paulo, São Paulo

Codevarc - Conselho Regional de Desenvolvimento do Vale do Caí. (2010). Planejamento estratégico regional do Vale do Caí. São Sebastião do Caí, RS: [s.n]

Cooper, D. R.; \& Schindler, P. S. (2003). Métodos de pesquisa em administração. 7. ed. Porto Alegre: Bookman.

Daroit, D., \& Nascimento, L. F. (2000) (A busca da qualidade ambiental como incentivo à produção de inovações. In: Encontro Anual da Anpad, 24, 2000, Florianópolis. Anais... Florianópolis: ANPAD

Deegan, C. (2002). The legitimising effect of social and environmental disclosures: a theoretical foundation. Accounting, Auditing \&Accountability Journal. 15(3), 282-311

Delmas, M.; Toffel, M. W. (2004). Stakeholders and environmental management practices: an institutional framework. Business Strategy and the Environment, 13(4), 209-222.

Donaire, D. (1999) Gestão ambiental na empresa. 2. ed. São Paulo: Atlas

Eckert, A. (2013) Teoria da Contabilidade. 2. ed. São Paulo: Edipro

Eckert, A., Corcini Neto, S. L. H., \& Boff, D. S. (2015). Iniciativas e práticas ambientais das pequenas e médias empresas do Vale do Caí-RS. Revista de Gestão Ambiental e Sustentabilidade, 4(1), 108-123.

Elkington, J. (1998). Partnerships from Cannibals with forks: The Triple Bottom Line of 21'Century Business. Environmental Quality Management, 14(3), 37-51.

Ethos, Instituto. (2016) Indicadores Ethos para Negócios Sustentáveis e Responsáveis: Ciclo 2015/2016. Disponível em: <http://www3.ethos.org.br/cedoc/indicadores-ethospara-negocios-sustentaveis-e-responsaveis/\#.V4zXRIn3PVJ > Acesso em: 18 jul. 2016.

Fee - Fundação de Economia e Estatística do RS (2011). - Corede Vale do Caí. Disponível em:http://www.fee.tche.br/sitefee/pt/content/resumo/pg_coredes_detalhe. php?corede=Vale+do+Ca\%ED> Acesso em: 24 out. 2016.

Feldmann, Fabio José; Furriela, Rachel Biderman. (2001). Los cambios climáticos globales y el desafío de la ciudadanía planetária. Acta Bioethica; 2(1), 1-27.

Ferreira, M. C. (2013). Gestão ambiental: um estudo em empresas do setor sucroalcooleiro em Goiás. RPCA - Revista do Pensamento Contemporâneo em Administração. 7(3), 59-80.

Fombrun, C. J. (1996). Reputation: realizing value from the corporate image. Boston: Harvard Business Press

Fugiel, A., Burchart-Korol, D., Czaplicka-Kolarz, K., \& Smoliński, A. (2017). Environmental impact and damage categories caused by air pollution emissions from mining and quarrying sectors of European countries. Journal of cleaner production, 143(1), 159-168. 
Gamba, C, \& Ribeiro, W. C. (2013). A encruzilhada brasileira na ordem ambiental internacional das mudanças climáticas. Revista Estudos Avançados, 27(78), 78-92.

Herrero, L.M.J. (2001). Desarrollo Sostenible y Economía Ecológica: Integración medio ambiente-desarrollo y economia-ecológia. Madrid-España: Sintesis.

Hubbard, G. (2009). Measuring Organizational Performance: Beyond the Triple Bottom Line. Business Strategy and the Environment, 19(1), 177-191.

Hunt, C. B., \& Auster, E. R. (1990). Proactive environmental management: avoiding the toxic trap. Sloan Management Review, EUA: Putnam, Hayes \& Bartlett, Winter

Keller, Garine Andréa. (2011). Conceptualização de Serra Gaúcha no Discurso Turístico Publicitário. Universidade de Caxias do Sul. Disponível em: https://repositorio.ucs. br/xmlui/bitstream/handle/11338/616/Dissertacao\%20Garine\%20Andrea\%20Keller. pdf?sequence=1\&isAllowed=y. Acesso em: 14 de abril de 2018.

Layarargues, Philippe Pomier. (2002). O cisnismo da reciclagem: o significado ideológico da reciclagem da lata de alumínio e suas implicações para a educação ambiental. Educação Ambiental: repensando o espaço da cidadania. p. 179-220. Disponível em: < https://docslide.com.br/documents/o-cinismo-da-reciclagem-capitulo-de-livro-2002pdf. html> Acesso em 21 de abril de 2018.

Lima Filho, R. N., Bruni, A. L., \& Gomes, S.M.S. (2013). A compreensão dos estudantes sobre o conceito de Passivo Ambiental: um estudo nos cursos de Ciências Contábeis em Salvador - BA. Revista do Pensamento Contemporâneo em Administração. 7(1), 108-121.

Marion, José Carlos, \& Santos, Marcia Carvalho. (2001). Os dois lados de uma profissão. Pensar Contábil, 4(13), 65-90.

Martendal, A., Vieira, E.M. F., Uhlmann, V.O., \& Pfitscher, E. D. (2013). Contabilidade Ambiental: nível de conhecimento dos profissionais contábeis da grande Florianópolis. Enfoque Reflexão Contábil. 32(1), 29-47.

May, T. (2004) Pesquisa Social: questões, métodos e processos. Trad. Soares, C.A.S.N., 3.ed. Porto Alegre: Artmed

Miranda, Luiz Carlos; Libonati, Jeronymo José; Freire, Deivisson Rattacaso; Saturnino, Odilon. (2008). Demanda por Serviços Contábeis pelos Mercadinhos: são os Contadores Necessários? Contabilidade Vista \& Revista. 19(1), 131-151.

Moreno, E., \& Pol, E. (1999). Nociones psicosociales para la intervención y la gestión ambiental. Monografies Socio-Ambientals, 14. Barcelona: Publicacions Universitat de Barcelona

Nagan, Marcelo Seido; Merlo, Edgard Monforte; Braga Junior, \& Sergio Silva. (2009). Um estudo comparativo das práticas de logística reversa no varejo de médio porte. Revista da Micro e Pequena Empresa, 3(1), 64-81. 
Naime, Roberto; Bemvenuti, Abel; Santos, Karin Luise, \& Michaelsen, Jaqueline. (2011). Novos procedimentos em Gestão Ambiental e busca de sustentabilidade em empresas do Vale do Rio dos Sinos. Ingepro - Inovação, Gestão e Produção, 3(2), 50-76.

Niesten, E., Jolink, A., de Sousa Jabbour, A. B. L., Chappin, M., \& Lozano, R. (2017). Sustainable collaboration: The impact of governance and institutions on sustainable performance. Journal of cleaner production, 155(1), 1-26.

Nossa, V. (2002). Disclosure ambiental: uma análise do conteúdo dos relatórios ambientais de empresas do setor de papel e celulose em nível internacional. Tese Doutorado em Controladoria e Contabilidade. Universidade de São Paulo, São Paulo Oliveira, A.B.S. (2011). Métodos da Pesquisa Contábil. São Paulo: Atlas

Paiva, P.R. (2003). Contabilidade Ambiental: evidenciação dos gastos ambientais com transparência e focada na prevenção. São Paulo: Atlas

Pol, E. (2003). A gestão ambiental, novo desafio para a psicologia do desenvolvimento sustentável. Estudos de Psicologia, 8(2), 235-243.

Ramos, Gilmara Cristina. (2004). Turismo e Meio Ambiente. UniFMU - Faculdades Metropolitanas Unidas. São Paulo. Disponível em: <http://arquivo.fmu.br/prodisc/ direito/gcr.pdf>. Acesso em 14 de abril de 2018.

Richardson, R. J. (1989). Pesquisa Social: métodos e técnicas. São Paulo: Atlas

Rmsg - Região Metropolitana da Serra Gaúcha (2019). Atlas Socioeconômico do RS. Disponível em<http://www.atlassocioeconomico.rs.gov.br/conteudo.asp?cod_menu_ filho=807\&cod_menu=805\&tipo_menu=POPULA\&cod_conteudo=1610> Acesso em: 12 jul. 2019.

Rohrich, S.S., \& Cunha, J.C. (2004). A Proposição de uma Taxonomia para Análise da Gestão Ambiental no Brasil. RAC, 8(4), 81-97.

Santos, P.M.F., \& Porto, R.B. (2013). Agestão ambiental como fonte de vantagem competitiva sustentável: contribuições da visão baseada em recursos e da teoria institucional. Revista de Ciências da Administração. 15(35), 142-167.

Schaltegger, S., Benett, M., \& Burritt, R. (Eds). (2006). Sustainability, Accounting and Reporting. Dordrecht: Springer

Sebrae - Serviço Brasileiro de Apoio às Micro e Pequenas Empresas (2020). Porte de estabelecimentos segundo o número de empregados. Disponível em: <https://www.sebrae. com.br/Sebrae/Portal\%20Sebrae/UFs/SP/Pesquisas/MPE_conceito_empregados.pdf> Acesso em: 07 dez. 2020.

Severo, L.S., \& Pedrozo, E. A. (2008). A citricultura orgânica na região do Vale do Caí (RS): racionalidade substantiva ou instrumental? RAM - Revista de Administração Mackenzie, 9(2), 53-85. 
Silva, J.C.T., Silva, M.S.T., \& Manfrinato, J.W.S. (2005). Correlação entre gestão da tecnologia e gestão ambiental nas empresas. Revista Produção, 15(2), 198-220.

Singla, A., Sethi, A. P. S., \& Ahuja, I. S. (2018). A study of transitions between technology push and demand-pull strategies for accomplishing sustainable development in manufacturing industries. World Journal of Science, Technology and Sustainable Development. Research paper. https://doi.org/10.1108/WJSTSD-09-2017-0028

Souza, Renato Santos. (2002). Evolução e condicionantes da Gestão Ambiental nas empresas. Revista Eletrônica de Administração, 8(6), 112-132.

Storey, D.J. (2003). Entrepreneurship, small and medium sized enterprises and public policies. In: Audretsch, D.B.; Acs, Z.J. (Eds). Handbook of Entrepreneurship Research, Kluwer Academic Publishers, Boston: MA.

Tauchen, J., \& Brandli, L. L. (2006). A gestão ambiental em instituições de ensino superior: modelo para implantação em campus universitário. Gestão \& Produção, 13(3), 503515.

Tinoco, J.E.P., \& Robles, L.T. (2006). A contabilidade da gestão ambiental e sua dimensão para a transparência empresarial: estudo de caso de quatro empresas brasileiras com atuação global. RAP. 40(6), 1077-1096.

Tomazzoni, Edegar Luis. (2006). Análise do discurso turístico da serra gaúcha. Em questão. 2(2), 1-29.

Ucs - Universidade de Caxias do Sul. (2013). - Instituto de Materiais Cerâmicos é referência no setor. Disponível em: http://www.ucs.br/site/ucs/tplNoticias/noticias/1330976523/ Acesso em: 24 nov. 2017.

Viegas, C., \& Fracasso, E. M. (1998). Capacidade tecnológica e gestão de resíduos em empresas de calçados do Vale dos Sinos: Estudo de dois casos. Revista de Administração Contemporânea, 2(2), 41-62.

\section{Dados dos autores:}

\section{Sabrina Keli Salvador}

(iD) ORCID: http://orcid.org/0000-0003-2254-6031

Especialização em Planejamento Tributário Contábil. Pesquisadora voluntária na Universidade de Caxias do Sul (UCS) no Programa de Pós-Graduação em Administração. Caxias do Sul, Rio Grande do Sul, Brasil. E-mail: sabrina.keli23@hotmail.com.

\section{Alex Eckert}

ORCID:

http://orcid.org/0000-0002-8704-9549

Doutorado em Administração. Professor na Universidade de Caxias do Sul (UCS) no Programa de Pós-Graduação em Administração. Caxias do Sul, Rio Grande do Sul, Brasil. E-mail: aeckert@ucs.br. 


\section{Marlei Salete Mecca}

ORCID: http://orcid.org/0000-0001-7545-3184

Doutorado em Engenharia da Produção. Professora na Universidade de Caxias do Sul (UCS) no Programa de Pós-Graduação em Administração. Caxias do Sul, Rio Grande do Sul, Brasil. E-mail: msmecca@ucs.br.

\section{Jéssica Santos Vargas}

(iD) ORCID: http://orcid.org/0000-0001-5254-5836

Especialização em Administração de Empresas. Pesquisadora voluntária na Universidade de Caxias do Sul (UCS) no Programa de Pós-Graduação em Administração. Caxias do Sul, Rio Grande do Sul, Brasil. E-mail: jeh.svargas@gmail.com.

\section{Como citar este artigo:}

Salvador, S. K., Eckert, A., Mecca, M. S., \& Vargas, J. S. (2021). Sustentabilidade e Governança: Evidenciação Ambiental em Empresas Prestadoras de Serviço. AOS Amazônia, Organizações e Sustentabilidade, 10(2). http://dx.doi.org/10.17648/aos.v10i2.1057 